\title{
Borrelia burgdorferi ile Doğal Enfekte Köpeklerin Nötrofil-Lenfosit, Monosit- Lenfosit ve Platelet-Lenfosit Oranlarının Belirlenmesi*
}

\author{
Kübra Çakır1', Didem Pekmezci² \\ ${ }^{1}$ Vet-life Veteriner Kliniği, Kartepe, Kocaeli, Türkiye \\ ${ }^{2}$ Ondokuz Mayıs Üniversitesi Veteriner Fakültesi İç Hastalıkları Anabilim Dalı, Samsun, Türkiye
}

Geliş Tarihi / Received: 13.05.2019, Kabul Tarihi / Accepted: 10.06.2019

\begin{abstract}
Özet: Lyme hastalığı ya da Borreliozis; Borrelia burgdorferi adlı spiroket şekilli bir bakterinin neden olduğu, dünyada köpeklerde ve insanlarda yaygın olarak görülen, başlıca Ixodes cinsi kenelerle bulaşan, kalp, eklemler ve sinir sisteminde bozukluklarla karakterize ve kronikleşebilen enfeksiyöz bir hastalıktır. Günümüzde sistemik inflamatuar yanıtın komplementleri olan nötrofil-lenfosit oranı (NLO), monosit-lenfosit oranı (MLO) ve platalet-lenfosit oranı (PLO) birçok hastalık prognozunun değerlendirilmesi ve prediktif parametreler olarak kullanılmaktadır. Bu çalışmadaki amacımız ise ilk defa kronik bir inflamasyona neden olan $B$. burgdorferi'i yönünden doğal enfekte seropozitif köpekler ile seronegatif köpeklerin tedavi öncesi başüstü parametreleri olan nötrofil (NEU), NLO, lenfosit (LYM), monosit (MONO), MLO, platalet (PLT) ve PLO değerlerinin karşılaştırılmasıdır. Yirmi dört adet sahipli köpekten tedavi öncesi alınan tam kan ve serum örnekleri çalışma materyalini oluşturmuştur. Serum örneklerinin $B$. burgdorferi'ye karş1 oluşan IgG antikor yanıtı ELISA yöntemi ile belirlenmiştir. Sonrasında bu 7 adet seropozitif örnek Western Blot yöntemi ile doğrulanmıştır. Gruplar arası NEU, NLO, MONO, MLO, PLT ve PLO değerleri karşılaştırılmış ancak, istatiksel bir fark bulunamamıştır. Sonuç olarak lyme hastalığ1 yönünden seropozitif köpekler ile seronegatif köpeklerin ilk kez NLO, MLO, ve PLO değerlerinin karşılaştırıldığı mevcut çalışma ile uygulaması kolay ve düşük maliyetli sistemik inflamasyon belirteçlerinin veteriner pratikteki kullanımlarının genişletilmesi yönündeki gerçekleştirilecek çalışmalara katkı sağlayacağı düşünülmektedir.
\end{abstract}

Anahtar kelimeler: Köpek, Borrelia burgdorferi, nötrofil-lenfosit, monosit-lenfosit, platelet-lenfosit, oran

\section{Detection of Neutrophil-Lymphocyte, Monocyte- Lymphocyte and Platelet-Lymphocyte Ratios in Dogs Naturally İnfected with Borrelia burgdorferi}

\begin{abstract}
Lyme disease or Borreliosis; is a commonly seen infectious disease in the dogs and men worldwide which caused by a spirochete shaped bacterium called B. burgdorferi, mainly transmitted with the Ixodes species of ticks and affects heart, joints and characterized with neurological system disorders. Nowadays, as being components of the systemic inflammatory response, the neutrophil-lymphocyte (NLR), monocyte-lymphocyte (MLR) and plateletlymphocyte ratios (PLR) are used as predicting parameters for the evaluation of the progression of various diseases. Our interest in the current study is to determine whether pretreatment NEU, NLR, LYM, MONO, MLR, PLT and PLR levels as bedside markers, differ in seropositive dogs naturally infected with B. burgdorferi which leads a chronic inflammation from seronegative dogs for the first time. Twenty four whole blood and serum samples of the client-owned dogs formed the study material. Seven of the serum samples were showed IgG against $B$. burgdorferi by ELISA and detected as seropositive. Later these 7 seropositive dogs were confirmed by Western Blot method. NEU, NLR, MONO, MLR, PLT and PLR levels were compared between groups, but there were not found any statistical significance for these parameters between groups. Consequently, it is thought that within this study, which firstly compared the NLO, MLO, and PLO values of seropositive dogs and seronegative dogs in terms of Lyme disease, is thought to contribute to the studies to be carried out in order to expand the use of these easily applicable and low cost systemic inflammation markers in veterinary practice.
\end{abstract}

Key words: Dog, Borrelia burgdorferi, neutrophil-lymphocyte, monocyte-lymphocyte platelet-lymphocyte, ratio

\section{Giriş}

Lyme hastalığı ya da Borreliozis; Borrelia burgdorferi adlı spiroket şekilli bir bakterinin neden olduğu, dünyada yaygın olarak görülen, başlica Ixodes cinsi kenelerle bulaşan, kalp, eklemler ve sinir sistemin- de bozukluklarla karakterize, ancak birçok organı da etkileyen ve kronikleşebilen enfeksiyöz bir hastalıktır. Köpek Borreliozis'i ise ilk kez 1980'lerde Amerika Birleşik Devletleri'nde tanımlanmış ve kısa zamanda tüm dünyaya yayılmıştır [9].

* Bu çalışma Kübra Çakır'ın Yüksek Lisans Tez'inden üretilmiştir.

Yazışma adresi / Correspondence: Vet. Hekim Kübra Çakır, (ORCID: 0000-0001-7488-1400), Vet-life Veteriner Kliniği, Kartepe, Kocaeli E-posta:k_yarimbas@hotmail.com 
Köpeklerde Lyme hastalığı birçok organ ve sistemi etkilemekte birlikte, en s1k eklemlerin etkilendiği rapor edilmiştir $[7,10]$. Hastalık her yaştaki köpekte eroziv olmayan artritis, topallık, ağrı, ateş $\left(\mathrm{T}>39,5^{\circ} \mathrm{C}\right)$, iştahsızlık, lenfadenopati ve yorgunluk şeklinde görülürken, yaşlı köpeklerde böbrek yetmezliğinin daha sık görüldüğü belirlenmiştir [10]. Miyokarditis ve endokarditis gibi kardiak bozuklukların hastalıkta nadir olarak oluştuğu ortaya konulmuştur [7].

Köpeklerde lyme hastalığının eroziv veya eroziv olmayan artrit formlarının dişında şekillenen nefropati formunda ödemli vaskülit veya efüzyon; olas1 körlük veya kalp üfürümlü hipertansiyon; tromboembolik olaylar ve bazen vaskülit, hipertansiyon, üremik ensefalopati veya menenjitin nörolojik belirtileri (örneğin, nöbet, nistagmus, kollasps) gibi semptomlar görülebilmektedir [4, 20].

$\mathrm{Bu}$ sendromdaki laboratuvar anormalliklerini ise dejeneratif olmayan anemi, stres lökogramı, trombositopeni, hipoalbuminemi, azotemi, hiperkolesterolemi, hiperfosfatemi ve bazen hiperkalemi ve hiperbilirubinemi oluşturmaktadır. İdrar muayenesinde proteinüri ve hemoglobinüri, hematüri, glukozüri, bilirubinüri ve negatif bakteri kültürü ile aktif bir sedimentasyonda azalma görülebilmektedir. Çoğu vaka oligürik veya anürik olup böbrek yetmezliği nedeni ile hasta köpekler ölebilmektedir $[6,4,15,20]$.

Çoğu zaman immun ilişkili mediyatörlerin oldukça geniş ve karmaşık sıraya sahip olmaları, kritik hastalıklarda immun yanıtın değerlendirilmesinde kullanılacak uygun biyokimyasal parametrelerden iyi bir prediktif belirteç olarak yararlanmayı mümkün kılmamaktadır [5]. Son zamanlarda hali hazırda kolaylıkla elimizin altında bulunan tam kan sayımından köken alan oranlar, henüz herhangi bir konsensus oluşturulmamasına rağmen potansiyel biyokimyasal belirteçler olarak beşeri hekimlikte yaygın olarak kullanılmaktadır [14, 16, 26].

Glasgow Prognostik Skoru'nun yanında sistemik inflamatuar yanıtın komplementleri olarak nötrofil-lenfosit oran1 (NLO), monosit-lenfosit oran1 (MLO) ve platalet-lenfosit oranı (PLO) yer almaktadır $[8,18]$. Son zamanlarda bu oranlar karsinogenezis ve tümör progresyonun değerlendirilmesinin yanı sıra birçok inflamasyon ilişkili hastalıklarda örneğin kardiyovasküler hastalıklar [13], malignan- siler [22], otoimmun hastal1klar [3, 24], akut pankreatitis [23], kronik obstruktif pulmoner hastalıklar $[12,25]$, overiyan apselerde, Chron hastalı̆̆ ve siroziste prognozun değerlendirilmesinde prediktif parametreler olarak kullanılmaktadır [1]. Ucuz ve kolaylıkla erişilebilecek olan bu oran ve skorlamaların henüz veteriner hekimlikte kullanılması için çok sayıda kapsamlı çalışmalara ihtiyaç vardır.

$\mathrm{Bu}$ çalışmanın amacı ise ilk defa kronik bir inflamasyona neden olan B. burgdorferi' nin neden olduğu lyme hastalığ1 yönünden seropozitif köpekler ile seronegatif köpeklerin NEU, NLO, MONO, MLO, PLT ve PLO değerlerinin karşılaştırılmasıdır.

\section{Materyal ve Metot}

\section{Çalışma Materyali}

Çalışma materyalini, Nisan 2017 ile Haziran 2018 tarihleri arasında Ondokuz Mayıs Üniversitesi Veteriner Fakültesi Eğitim Uygulama ve Araştırma Hastanesi'ne tedavi veya kontrol amaciyla getirilen sahipli, çeşitli ırk ve yaşlarda, dişi ve erkek toplam 24 adet köpek oluşturmuştur. Çalışmaya daha önce B. burgdorferi'ye karşı aşılanmamış ve Lyme hastalığ1 yönünden herhangi bir tedavi görmemiş toplam 24 adet köpek dâhil edilmiştir. Serolojik olarak $B$. burgdorferi yönünden pozitif kabul edilen 7 adet köpek deney grubunu oluştururken, geriye kalan ve serolojik olarak negatif kabul edilen 17 adet köpek ise kontrol grubunu oluşturmuştur. Çalışma yerel hayvan etik kurulunca onaylanmıştır (2016/64).

\section{Total Kan Sayımı}

Rutin muayenede tedavi öncesi 2 ml EDTA'lı tüplere, $5 \mathrm{ml}$ kuru tüplere alınmış olan kan örnekleri çalışma materyali olarak kullanılmıştır. EDTA'lı tüplere alınan kan örnekleri total kan sayımı için sayım öncesi karıştırıcıda orta devirde karıştırılıp çalışı1maya hazır hale getirilmiş, sonrasında 24 adet tam kan örneği BC-5000 Vet Auto Hematoloji cihazıyla çalışılmış ve sonuçlar (WBC, NEU, LYM, MONO, EOS, LY\%, MONO \%, EOS \%, NEU\%, RBC, HGB, HCT, MCV, MCH, MCHC, RDW-CV, RDW-SD, PLT, PCT, MPV, PDW) kayıt altına alınmıştır. Çalışma köpeklerine ait tam kan sayımı değerlerinden NLO (nötrofil/lenfosit), MLO (monosit/lenfosit) ve PLO (platelet/lenfosit), lenfosit sayılarının sıras ile nötrofil, monosit ve platelet sayılarına ayrı ayrı 
bölünerek hesaplanmasından elde edilmiștir [19]. Lyme hastalığının serolojik tanısı amacıyla jelli tüplere alınan örnekler 3000 rpm'de 10 dakika santrifüj edilerek serumları 2 farklı ependorf tüpüne aktarılarak çalışılana kadar $-20{ }^{\circ} \mathrm{C}^{\prime}$ de muhafaza edilmiştir.

Serolojik Olarak Köpek Spesifik Anti $B$. burgdorferi IgG Seviyelerinin ELISA Yöntemi ile Tespiti

Köpeklerden alınan serum örnekleri öncelikle $B$. burgdorferi'ye karşı oluşan IgG antikor yanıtını belirlemek amacı ile EUROIMMUN ${ }^{\circledR}$ Anti-Borrelia ELISA Köpek IgG (Lübeck, Germany) kitleriyle üretici firmanın direktiflerine uygun olarak çalışı1mış ve 450 nm'de ELISA okuyucuda okutulmuştur. Elde edilen okuma değerleri prospektüste belirtilen yönteme göre hesaplanmış ve test sonucunda kalibrasyona ait değerlere bölünerek son değerlere ulaşılmıştır. Her bir örneğin pozitif, negatif ya da sınırda pozitifliği belirlenmiştir.

\section{Serolojik Olarak Köpek Spesifik Anti $B$. burgdorferi IgG Pozitif Köpeklerin Western Blot Yöntemi ile Doğrulanması}

ELISA yöntemi ile pozitif bulunan serum örnekleri, EUROIMMUN ${ }^{\circledR}$ Anti-Borrelia EUROLINE Köpek IgG (Lübeck, Germany) kitleri ile çalışılmıştır. Test görsel olarak değerlendirilmiş olup, her bir örneğin verdiği bant sayısı ve çeşidine göre değerlendirme yapılmıştır. Spesifik antijen bant değerlendirmesinde; VIsE, P100, P39, OspA (p31), OspC (P25), p21, p18 yer almaktadır. Sonuçlar üretici firmanın direktiflerine göre firmanın göndermiş olduğu test kontrol kâğıtlarının üzerinde görsel olarak değerlendirilmiştir.

\section{İstatistiksel Analiz}

Çalışmaya dâhil edilen tüm köpeklerin NEU, LYM, MONO, PLT, NLO, MLO ve PLO değerlerinin normal dağılım gösterip göstermediğini belirlemek amacı ile Kolmogorov-Smirnov testi kullanılmıştır. Sonrasinda deney ve kontrol grubu arasında NEU, LYM, MONO, PLT, NLO, MLO ve PLO değerlerinin karşılaştırılmasında ise Student $t$ testi uygulanmiştır.

\section{Bulgular}

Çalışma materyalini oluşturan 24 köpeğin, 7'si $B$. burgdorferi'ye karşı oluşan anti IgG antikor yönünden seropozitif olarak bulunurken, 17 köpek seronegatif olarak tespit edilmiștir (Tablo 1). Deney grubunu oluşturan 7 köpeğin seropozitiflikleri ise sonrasında Western Blot yöntemi ile doğrulanmıştır. Deney ve kontrol gruplarına ait NEU, LYM, MONO, PLT değerleri Figür 1'de gösterilmiştir. Deney ve kontrol gruplarına ait NLO, MLO, PLO değerleri ise Figür 2'de gösterilmiştir.

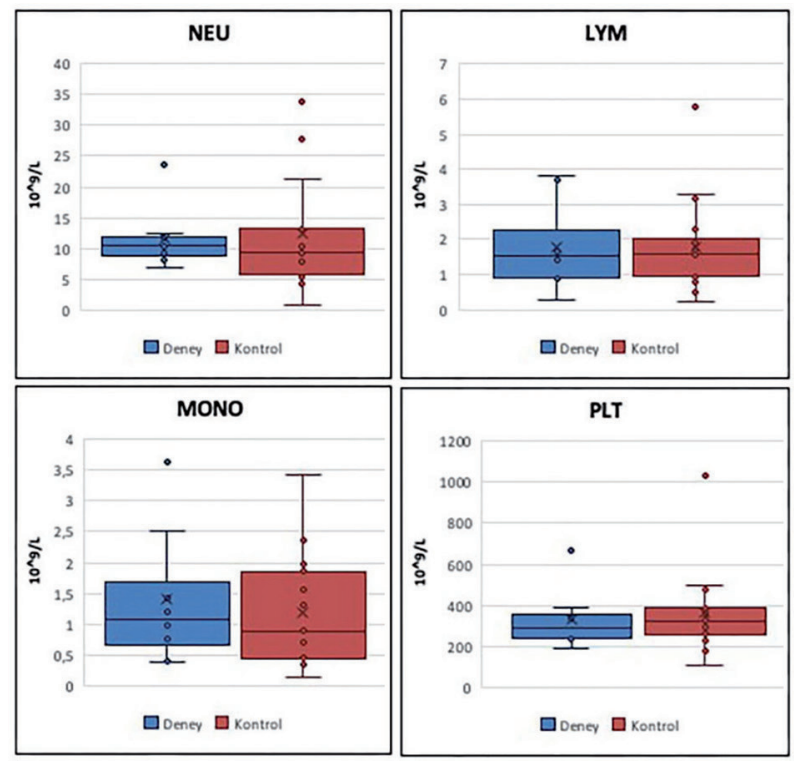

Figür-1: Borrelia burgdorferi ile doğal enfekte seropozitif (Deney grubu; mavi renkli) ve seronegatif köpeklerin (Kontrol grubu; kırmızı renk) tedavi öncesi NEU, LYM, MONO ve PLT değerlerinin sunulduğu Kutu-Bıyık grafikleri (Box-and-whiskers plot). Orta Kutu, gözlemin \%50'sini oluşturmaktadır; kutunun alt kısmı birinci çeyrekliği ve kutunun üstü üçüncü çeyrekliği oluşturmaktadır. Kutunun ortasındaki yatay çizgi ise medyandır. Her kutudaki çarpı işareti o kutuya ait ortalama değeri vermektedir. Bıyıklar, çeyrekler arası aralıktan 1,5 kez çıkartılan en küçük ve en büyük gözlemlere kadar uzanmaktadır ve ayrı ayrı noktalar halinde belirtilmişlerdir. 


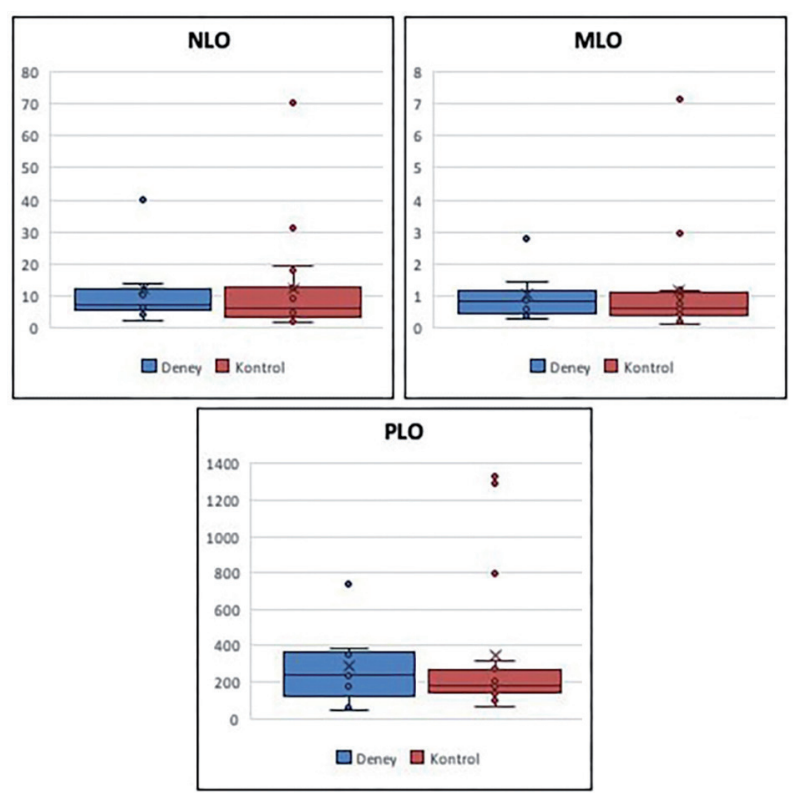

Figür-2: Borrelia burgdorferi ile doğal enfekte seropozitif (Deney grubu; mavi renkli) ve seronegatif köpeklerin (Kontrol grubu; kırmızı renk) tedavi öncesi NLO, MLO ve PLO değerlerinin sunulduğu Kutu-Bıyık grafikleri (Box-and-whiskers plot). Orta Kutu, gözlemin \%50'sini oluşturmaktadır; kutunun alt kısmı birinci çeyrekliği ve kutunun üstü üçüncü çeyrekliği oluşturmaktadır. Kutunun ortasındaki yatay çizgi ise medyandır. Her kutudaki çarpı işareti o kutuya ait ortalama değeri vermektedir. Biyıklar, çeyrekler arası aralıktan 1,5 kez çıkartılan en küçük ve en büyük gözlemlere kadar uzanmaktadır ve ayrı ayrı noktalar halinde belirtilmişlerdir.

Tablo 1. Çalışma materyalini oluşturan 24 köpeğin ırk, yaş ve cinsiyetlerine ait veriler.

\begin{tabular}{|c|c|c|c|}
\hline \multicolumn{4}{|c|}{ Anti B. burgdorferi IgG yönünden pozitif köpekler } \\
\hline Irk & Yaş & Cinsiyet & Uygulama ve Araştırma Hastanesine Getiriliş Nedeni \\
\hline Golden Retriever & 8 & Dişi & Genel Muayene \\
\hline Rottweiler & 5 & Erkek & Belirtilmemiş \\
\hline Mastiff & 5 & Erkek & Topallık \\
\hline Akbaş & 5 aylık & Erkek & Gastritis \\
\hline Pointer & 6 aylık & Erkek & Çam Kese Böceği Toksikasyonu \\
\hline Doberman Pinscher & 10 & Dişi & Piyometra \\
\hline Golden Retriever & 11 & Dişi & Atopik Dermatit \\
\hline \multicolumn{4}{|c|}{ Anti B. burgdorferi IgG yönünden negatif köpekler } \\
\hline Irk & Yaş & Cinsiyet & Uygulama ve Araştırma Hastanesine Getiriliş Nedeni \\
\hline İngiliz Pointer & 1 & Erkek & Genel Muayene \\
\hline Golden Retriever & 6 & Erkek & Genel Muayene \\
\hline Melez & 6 aylık & Dişi & Belirtilmemiş \\
\hline Melez & 9 aylık & Dişi & Belirtilmemiş \\
\hline Setter & 2 & Erkek & Ovariohisterektomi \\
\hline Pointer & 1 & Erkek & Gastritis \\
\hline Alman Çoban Köpeği & 8 & Dişi & Genel Kontrol \\
\hline Kangal & 6 aylık & Dişi & Genel Kontrol \\
\hline Labrador Retriever & 9 & Dişi & Ovariohisterektomi \\
\hline Melez & 2 & Dişi & Genel Kontrol \\
\hline Melez & 8 aylık & Dişi & Genel Kontrol \\
\hline Melez & 4 aylık & Dişi & Genel Kontrol \\
\hline Melez & 4 aylık & Erkek & Genel Kontrol \\
\hline Melez & 15 & Dişi & Genel Kontrol \\
\hline Belçika Malinois & 1 & Erkek & Genel Kontrol \\
\hline Melez & 5 aylık & Erkek & Genel Kontrol \\
\hline Melez & 3 & Erkek & Genel Kontrol \\
\hline
\end{tabular}




\section{Tartışma}

Lyme hastalıkl1 insanlar ve köpeklerde hematolojik ve serum biyokimyasal değerler genellikle normal sinırlar içerisinde yer almaktadır [15]. Benzer sonuçlar çalışmamız içinde geçerli olmuştur. Zira deney grubuna ait ortalama NEU, LYM, MONO, PLT değerleri siras 1 ile $9,5 \times 10^{9} / \mathrm{L}, 2,05 \times 10^{9} / \mathrm{L}$, $0,742 \times 10^{9} / \mathrm{L}$ ve $318,68 \times 10^{9} / \mathrm{L}$ olarak bulunmuştur. $\mathrm{Bu}$ sonuçlar Scorpio ve ark. [21] yapmış oldukları çalışma ile benzerlik göstermektedir. Sunulan çalışmada deney ve kontrol grubunun NEU, LYM, MONO, PLT değerlerinin karşılaştırılmasında ise istatiksel olarak bir farkl111k $(\mathrm{P}>0.05)$ tespit edilememiştir.

Deney ve kontrol gruplarının NLO, MLO ve PLO değerlerinin karşılaştırılmasında ise yine istatiksel olarak bir farkl1lık $(\mathrm{P}>0.05)$ olmamakla beraber deney grubunun NLO ortalama değerinin $(7,2)$, kontrol grubuna göre $(5,2)$ yüksek olduğu belirlenmiştir. Bazı çalışmalarda lokal lenfositik yanıtın, invazif yapıdaki lenfositik reaksiyonlar gibi değerlendirilmeleri neticesinde düşük NLO oran1 ile karşılaşıldığını ve bunun sonucunda ise prognozun daha iyi olduğu bildirilmektedir [17]. Mevcut çalışmamızda kontrol grubuna kıyasla deney grubunun yüksek LYM değerine sahip olmasına rağmen yine deney NLO değerinin de yüksek olduğu tespit edilmektedir. Bu durum çalışmamızdaki deney ve kontrol grup örnek sayılarının düşük olması ile açıklanabilir. MLO değerleri bakımından mevcut çalışmada deney $(0,7)$ ve kontrol grubu $(0,6)$ karş1laştırılmasında yine istatiksel bir farklılık $(\mathrm{P}>0.05)$ bulunmamıştır.

Deney ve kontrol gruplarını PLT ve PLO değerleri bakımından karşılaştırılmalarında yine istatiksel bir farklılık $(\mathrm{P}>0.05)$ tespit edilememiştir. Bununla birlikte deney PLO değerinin $(241,2)$ kontrol grubuna göre $(182,8)$ yüksek bulunduğu tespit edilmiştir. Sonuçlarımız Scorpio ve ark. [21]'nın yapmış oldukları ve PLT bakımından seropozitif ve negatif köpekleri karşılaştırdıkları çalışma ile benzerlik göstermektedir. Araştırmacılar çalışmalarında seropozitif köpeklerin PLT değerlerinin $\left(286,78 \times 10^{9} / \mathrm{L}\right)$ seronegatif olanlara $(202,42$ $\mathrm{x} 10^{9} / \mathrm{L}$ ) istatiksel olarak bir farklılık göstermediğini tespit etmişlerdir [21]. Yapılan son çalışmalar plateletlerin sistemik inflamasyonda özellikle de athe- rogeneziste oldukça önemli bir role sahip olduğunu göstermektedir [11]. Plateletler birçok farklı hücre tipleri ile örneğin endoteliyal ve dendritik hücreler, T-lenfositler, ve mononükleer fagositler ile etkileşim içindedir [2]. Çalışmamızda lyme hastalıklı köpeklerde PLO'nun yükselme eğiliminde olduğu söylenebilir. Değerlendirmede PLO'nun yüksek bulunmas1 ise bu hastalardaki sistemik inflamasyonun da yüksek olabileceğini göstermektedir. Son y1llarda beşeri hekimlikte uygulama kolaylığı ve düşük maliyetinden ötürü NLO, MLO ve PLO değerleri sayısız hastalığın prognozunun değerlendirilmesinde kullanılmaktadır. Beşeri hekimlikte meta analizler doğrultusunda tüm inflamatuar yanıttaki sitokin ve akut faz proteinleri ile korrelasyonları valide edilmiş NLO, MLO ve PLO'nun B. burgdorferi yönünden seropozitif ve negatif köpeklerde değerlendirildiği çalışmamızda örnek sayımızın her iki grupta az olması çalışmamızı kısıtlayan en önemli nedeni oluşturmaktadır.

\section{Sonuç}

Kronik inflamasyona neden olan B. burgdorferi'nin neden olduğu lyme hastalığı yönünden seropozitif köpekler ile seronegatif köpeklerin ilk kez NLO, MLO ve PLO değerlerinin karşılaştırıldığı bu çalışmada, NLO ve PLO değerlerinin lyme yönünden seropozitif köpeklerde yükselme eğiliminde olduğu söylenebilir. Sonuç olarak, bu çalışma ile uygulaması kolay ve düşük maliyetli sistemik inflamasyon belirteçlerinin veteriner pratikteki kullanımlarının genişletilmesi yönünde gerçekleştirilecek çalışmalara katkı sağlayacağını düşünmekteyiz.

\section{Teșekkür}

Bu çalışma, Ondokuz Mayıs Üniversitesi tarafından PYO.VET.1904.17.020 proje numaras1 ile desteklenmiştir. Ayrıca çalışmanın istatistiğini yapan Prof. Dr. Filiz Akdağ’a şükranlarımızı sunarız.

\section{Kaynaklar}

1. Alay I, Kaya C, Karaca I, Eren E, Hosgoren M, Aslanova F, Cengiz ME, Yasar, L. (2019). The effectiveness of neutrophil to lymphocyte ratio in prediction of medical treatment failure for tubo-ovarian abscess. J Obstet Gynaecol Res. doi:10.1111/jog. 13946 
2. Borissoff JI, Spronk HM, ten Cate H, (2011). The hemostatic system as a modulator of atherosclerosis. N Engl J Med. 364, 1746-1776.

3. Chandrashekara S, Mukhtar Ahmad M, Renuka P, Anupama KR, Renuka K, (2017). Characterization of neutrophil-tolymphocyte ratio as a measure of inflammation in rheumatoid arthritis. Int J Rheum Dis. 20, 1457-1467.

4. Dambach DM, Smith CA, Lewis RM, Van Winkle TJ, (1997). Morphologic, immunohistochemical, and ultrastructural characterization of a distinctive renal lesion in dogs putatively associated with Borrelia burgdorferi infection: 49 cases (1987-1992). Vet Pathol. 34, 85-96.

5. Djordjevic D, Rondovic G, Surbatovic M, Stanojevic I, Udovicic I, Andjelic T, Zeba S, Milosavljevic S, Stankovic N, Abazovic D, Jevdjic J, Vojvodic D, (2018). Neutrophilto-lymphocyte ratio, monocyte-to-lymphocyte ratio, platelet-to-lymphocyte ratio, and mean platelet volume-to-platelet count ratio as biomarkers in critically ill and injured patients: Which ratio to choose to predict outcome and nature of bacteremia? Mediators Inflamm. 2018, 3758068.

6. Grauer GF, Burgess EC, Cooley AJ, (1988). Renal lesions associated with Lyme borreliosis in a dog. J Am Vet Assoc. 193, 237-239.

7. Greene RT, (1991). Canine Lyme borreliosis. Vet Clin N Am Small Anim. 21, 51-64.

8. Guthrie GJK, Charles KA, Roxburgh CSD, Horgan PG, McMillan DC, Clarke SJ, (2013). The systemic inflammation-based neutrophil-lymphocyte ratio: experience in patients with cancer. Crit Rev Oncol Hematol. 88, 218-230.

9. Koneman EW, Allen SD, Janda WM, Schreckenberger PC, Winn WC, (1997). Lyme disease. Color Atlas and Textbook of Diagnostic Microbiology, J.B. Lippincott Company, Philadelphia, p. 964-971.

10. Kornblatt AN, Urband PH, Stere AC, (1985). Arthritis caused by Borrelia burgdorferi in dogs. J Am Vet Med Assoc. 186, 960-964.

11. Koyama H, Maeno T, Fukumoto S, Shoji T, Yamane T, Yokoyama H, Emoto M, Shoji T, Tahara H, Inaba M, Hino M, Shioi A, Miki T, Nishizawa Y, (2003). Platelet P-selectin expression is associated with atherosclerotic wall thickness in carotid artery in humans. Circulation. 108, 524-529.

12. Kurtipek E, Bekci TT, Kesli R, Sami SS, Terzi Y, (2015). The role of neutrophil lymphocyte ratio and platelet-lymphocyte ratio in exacerbation of chronic obstructive pulmonary disease. J Pak Med Assoc. 65, 1283-1287.

13. Li H, Zhou Y, Ma Y, Han S, Zhou L, (2017). The prognostic value of the platelet-to lymphocyte ratio in acute coronary syndrome: a systematic review and meta-analysis. Kardiol Pol. 75, 666-673.

14. Liu X, Shen Y, Wang H, Ge Q, Fei A, Pan S, (2016). Prognostic significance of neutrophil-to-lymphocyte ratio in patients with sepsis: a prospective observational study. Mediators Inflamm. 2016, 8191254.
15. Magnarelli LA, Anderson JF, Schreier AB, (1987). Clinical and serologic studies of canine borreliosis, J Am Vet Med Assoc. 19, 1089-1094.

16. Naess A, Nilssen SS, Mo R, Eide GE, Sjursen H, (2017). Role of neutrophil to lymphocyte and monocyte to lymphocyte ratios in the diagnosis of bacterial infection in patients with fever. Infection, 45, 299-307.

17. Pine JK, Morris E, Hutchins GG, West NP, Jayne DG, Quirke P, Prasad KR, (2015). Systemic neutrophil-tolymphocyte ratio in colorectal cancer: the relationship to patient survival, tumor biology and local lymphocytic response to tumor. Br J Cancer. 113, 204-211.

18. Proctor MJ, Morrison DS, Talwar D, Balmer SM, Fletcher CD, O'Reilly DSJ, Foulis AK, Horgan PG, McMillan DC, (2011). A comparison of inflammation-based prognostic scores in patients with cancer. A Glasgow Inflammation Outcome Study. Eur J Cancer. 47, 2633-2641.

19. Rossi S, Basso M, Strippoli A, Schinzari G, D’Argento E, Larocca M, Cassano A, Barone C, (2017). Are markers of systemic inflammation good prognostic indicators in colorectal cancer? Clin Colorectal Cancer. 16, 264-274.

20. Sanders NA, (2000). Canine Lyme nephritis Proc. 18th ACVIM Forum, 627-628.

21. Scorpio DG, Wachtman LM, Tunin RS, Barat NC, Garyu JW, Dumler JS, (2008). Retrospective clinical and molecular analysis of conditioned laboratory dogs (Canis familiaris) with serologic reactions to Ehrlichia canis, Borrelia burgdorferi, and Rickettsia rickettsii. J Am Assoc Lab Anim Sci. 47, 23-28.

22. Shi L, Qin X, Wang H, Xia Y, Li Y, Chen X, Shang L, Tai YT, Feng X, Acharya P, Acharya, C, Xu Y, Deng S, Hao M, Zou D, Zhao Y, Ru K, Qiu L, An G, (2017). Elevated neutrophil-to-lymphocyte ratio and monocyte-to-lymphocyte ratio and decreased platelet-to-lymphocyte ratio are associated with poor prognosis in multiple myeloma. Oncotarget. 8, 18792-18801.

23. Wang Y, Fuentes HE, Attar BM, Jaiswal P, Demetria M, (2017). Evaluation of the prognostic value of neutrophil to lymphocyte ratio in patients with hypertriglyceridemia induced acute pancreatitis. Pancreatology. 17, 893-897.

24. Yang Z, Zhang Z, Lin F, Ren Y, Liu D, Zhong R, Liang Y, (2017). Comparisons of neutrophil-, monocyte-, eosinophil-, and basophil- lymphocyte ratios among various systemic autoimmune rheumatic diseases. APMIS. 125, 863-871.

25. Yao C, Liu X, Tang Z, (2017). Prognostic role of neutrophillymphocyte ratio and platelet- lymphocyte ratio for hospital mortality in patients with AECOPD. Int J Chron Obstruct Pulmon Dis. 12, 2285-2290.

26. Zheng CF, Liu WY, Zeng FF, Zheng MH, Shi HY, Zhou Y, Pan JY, (2017). Prognostic value of platelet-to-lymphocyte ratios among critically ill patients with acute kidney injury. Critical Care. 21, 238. 